\title{
A rare cause of biliary colic
}

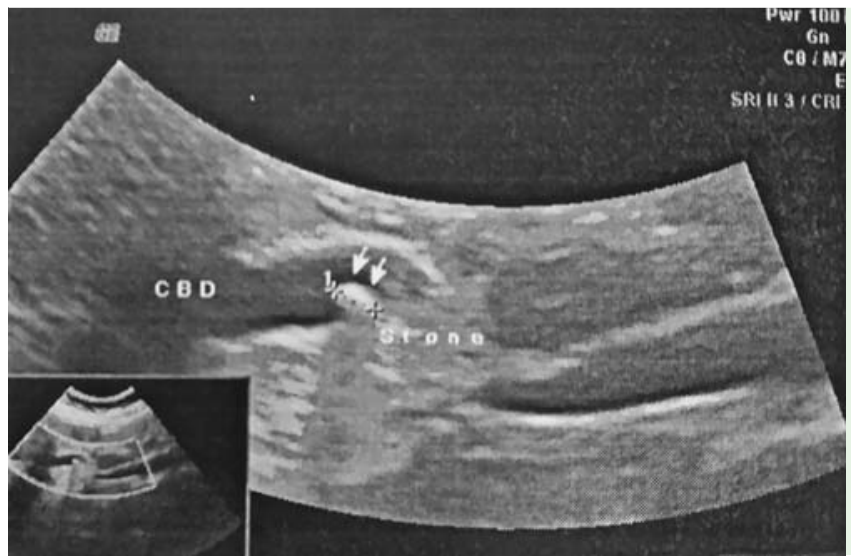

Fig. 1 Abdominal ultrasound image in a 29-year-old woman undergoing evaluation for recurrent biliary colic shows mild dilatation of the common bile duct with a web at its distal end (arrows), misdiagnosed as a small stone. CBD, common bile duct.

A 29-year-old woman presented to our center for the evaluation of recurrent biliary colic. Abdominal ultrasound revealed mild dilatation of the common bile duct (CBD) apparently with a small stone at its distal end ( $\bullet$ Fig. 1). The patient underwent endoscopic retrograde cholangiopancreatography (ERCP), which showed mild dilatation of the CBD but no stones. A horizontal filling defect was observed at the distal end of the CBD ( $\bullet$ Fig. 2). Lateral fluoroscopic examination showed a small biliary web ( $\bullet$ Fig.3). During a sweep of the CBD with the extraction balloon, mild resistance was encountered at the site of the web, which was then dilated with the balloon ( $\bullet$ Fig.4).

Biliary webs are rare, with approximately 20 cases reported in the literature [1]. Most biliary webs are associated with choledocholithiasis as a result of impaired biliary drainage [2]. Although the exact mechanism behind the formation of webs in the bile ducts is not known, some are believed to be congenital [3]. During the development of the human embryo, the bile ducts pass through a solid stage, in which the lumen becomes obliterated by epithelial proliferation [4]. Recanalization of the biliary tree usually starts at the end of the fifth week of gestation [4]. Incomplete recanalization can lead to the development of a web.

Biliary webs are typically diagnosed by contrast cholangiography or magnetic resonance imaging. Also, direct in vivo cholangioscopic imaging of a biliary web has been reported [5]. During more than 6 months of follow-up evaluation after balloon dilation of the web, our patient has not experienced any biliary problems.

\section{Endoscopy_UCTN_Code_CCL_1AZ_2AN}

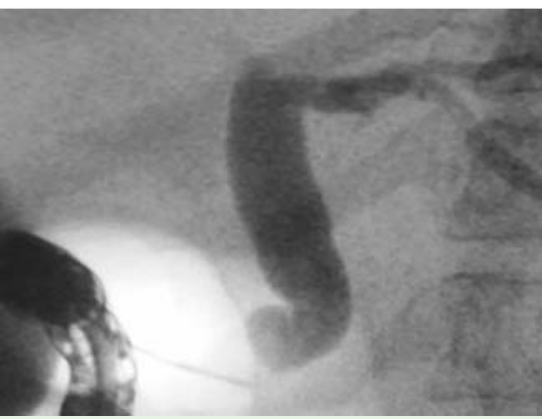

Fig. 3 Lateral fluoroscopic image shows a small biliary web.
Competing interests: None

\section{Ahmed Youssef Altonbary, Monir Hussein Bahgat}

Department of Hepatology and Gastroenterology, Mansoura Specialized Medical Hospital, Mansoura, Egypt

\section{References}

1 Shera AH, Shah OJ. Congenital common bile duct web in association with hepatobiliary pancreatic ductal anomalies. Eur J Pediatr Surg 2008; 18: $350-351$

2 Papaziogas B, Lazaridis C, Pavlidis $T$ et al. Congenital web of the common bile duct in association with cholelithiasis. J Hepatobiliary Pancreat Surg 2002; 9: 271-273

3 Kottoor R, Alvares JF, Devarbhavi H. Successful endoscopic therapy of an obstructing common bile duct web. Gastrointest Endosc 2001; 53: $126-128$

4 Ando $H$. Embryology of the biliary tract. Dig Surg 2010; 27: 87-89

5 Parsi MA. Biliary web: diagnosis with highdefinition videocholangioscopy. Clin Gastroenterol Hepatol 2014; 12: A29. DOI: 10.1016/j.cgh.2013.08.018. Epub 2013 Aug 16

\section{Bibliography}

DOI http://dx.doi.org/

10.1055/s-0034-1391874

Endoscopy 2015; 47: E277

(c) Georg Thieme Verlag KG

Stuttgart · New York

ISSN 0013-726X

\section{Corresponding author}

\section{Ahmed Youssef Altonbary, MD}

Department of Hepatology and Gastroenterology Mansoura Specialized Medical Hospital Mansoura

Egypt

a.tonbary@gmail.com

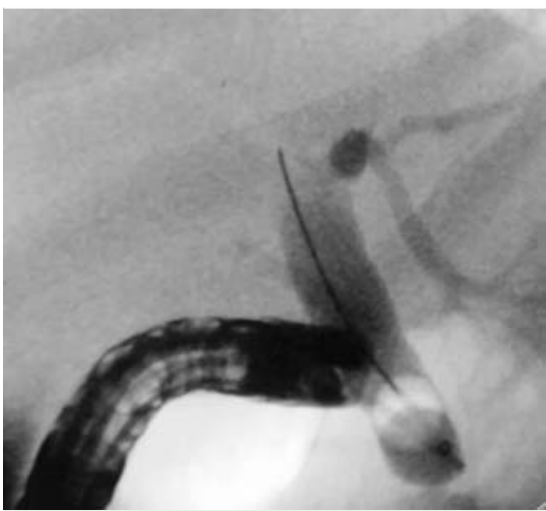

Fig.4 Balloon dilation of the web.
Fig. 2 Fluoroscopic image shows a horizonta filling defect at the distal end of the common

bile duct.



